\title{
AC 2010-393: FORCE BALANCE DESIGN FOR EDUCATIONAL WIND TUNNELS
}

\section{Martin Morris, Bradley University}

Martin Morris is a professor of Mechanical Engineering at Bradley University in Peoria, IL. He worked for 10 years at McDonnell-Douglas in St. Louis. His research interests include instrumentation, measurement techniques, and flow visualization techniques. His background includes extensive work in both internal and external compressible flows.He has also worked on pressure- and temperature-sensitive paints.

\section{Scott Post, Bradley University}

Scott Post is an assistant professor of Mechanical Engineering at Bradley University in Peoria, IL. He previously taught at Michigan Technological University, and worked as a summer faculty fellow at NASA Dryden Flight Research Center. His research interests include aerodynamics, fuel injectors and sprays, and diesel engines. 


\title{
Force Balance Design for Educational Wind Tunnels
}

\begin{abstract}
A typical educational wind tunnel need only measure the lift and drag forces and be able to control the angle of attack of the mounted model. This paper presents a simple design for the balance apparatus to measure lift and drag. Two load cells are used in the apparatus, one to measure the vertical force (lift) and one to measure the horizontal force (drag). This can be used for aerodynamics studies of airplane and airfoil models, as well as ground vehicles such as trucks and cars. If desired, a third load cell can be added to enable measurements of the pitching moment. A linear actuator is used to change the angle of attack of plane and airfoil models. The actuator is mounted inside the force balance apparatus, using a parallel four-bar linkage so that the angle of attack is linearly related to the actuator position. The linear actuator can be controlled by a computer, and the lift, drag, and angle of attack data recorded on the same computer. This design is simple and easy to fabricate, can be added to an old wind tunnel in need of an upgrade or replacement or included as part of a new wind tunnel built from scratch. Complete details of the design including engineering drawings are included in the paper. The design is also low cost compared to commercial wind tunnel balances and gives sufficient accuracy for educational and some research purposes. A counterweight is used to mechanically zero the force readout. The new load balance has been tested and found accurate. It has sufficient precision to perform a sting drag measurement as well. A quick-connect mechanism is used for mounting and removing models.
\end{abstract}

\section{Introduction}

Wind tunnels are a useful tool not only for aerospace engineers, but also for mechanical and civil engineers. From an educational point of view, in addition to measuring the aerodynamic forces on airplanes, wings, cars, trucks, bridges, and buildings, they can also be used to measure the aerodynamic forces on sports balls, partially open valves, and anything else that can be mounted on the mounting sting. There are many excellent references in the literature on wind tunnel testing and basic aerodynamics ${ }^{1-10}$ appropriate for undergraduate students. Blevins' handbook ${ }^{7}$ is particularly recommended as a source of drag coefficient data, and the NACA report ${ }^{8}$ a useful source of lift and drag data for airfoils. Most NACA reports can be found online on the NASA technical reports server (ntrs.nasa.gov).

Wind tunnel testing is not cheap, however. In addition to the cost of the wind tunnel itself, there is the requirement for the infrastructure to house the wind tunnel and the cost of electricity to run the tests. While a crude wind tunnel can be constructed relatively cheaply from a large fan and sheet metal, a wind tunnel is only useful for flow visualization without a force balance.

A full 6-component force and moment balance for a wind tunnel can easily cost in the tens of thousands of dollars, perhaps as much as the rest of the wind tunnel and equipment costs. This paper presents a design for a simple 2-component wind tunnel balance that can be easily fabricated at a basic machine shop, has accuracy sufficient for educational and even some research purposes, and costs about a thousand dollars. 


\section{History of Wind Tunnels}

The history of wind tunnels is discussed in references ${ }^{3,11-13}$. The first wind tunnel was built by Francis Wenham in 1871 . The $19^{\text {th }}$ century wind tunnels were generally straight of uniform cross-section connected to a fan. The Wright Brothers were really the first to show the value of the wind tunnel in aerodynamic design with their 1902 wind tunnel. They were able to deduce empirically that long aspect ratio wings were more efficient than short stubby ones, a fact which Prandtl later proved analytically. The Wright Brothers' wind tunnel was largely made of wood, with a glass window on the top to look down through and see the force balance, from which the lift and drag force could be read. The wind tunnel was powered by a fan driven off a natural gas fueled engine that was also used to power the machine tools in their bicycle shop. Their tunnel was square with an area of 16" by 16", and 6 foot long, with a maximum test speed of $35 \mathrm{mph}$.

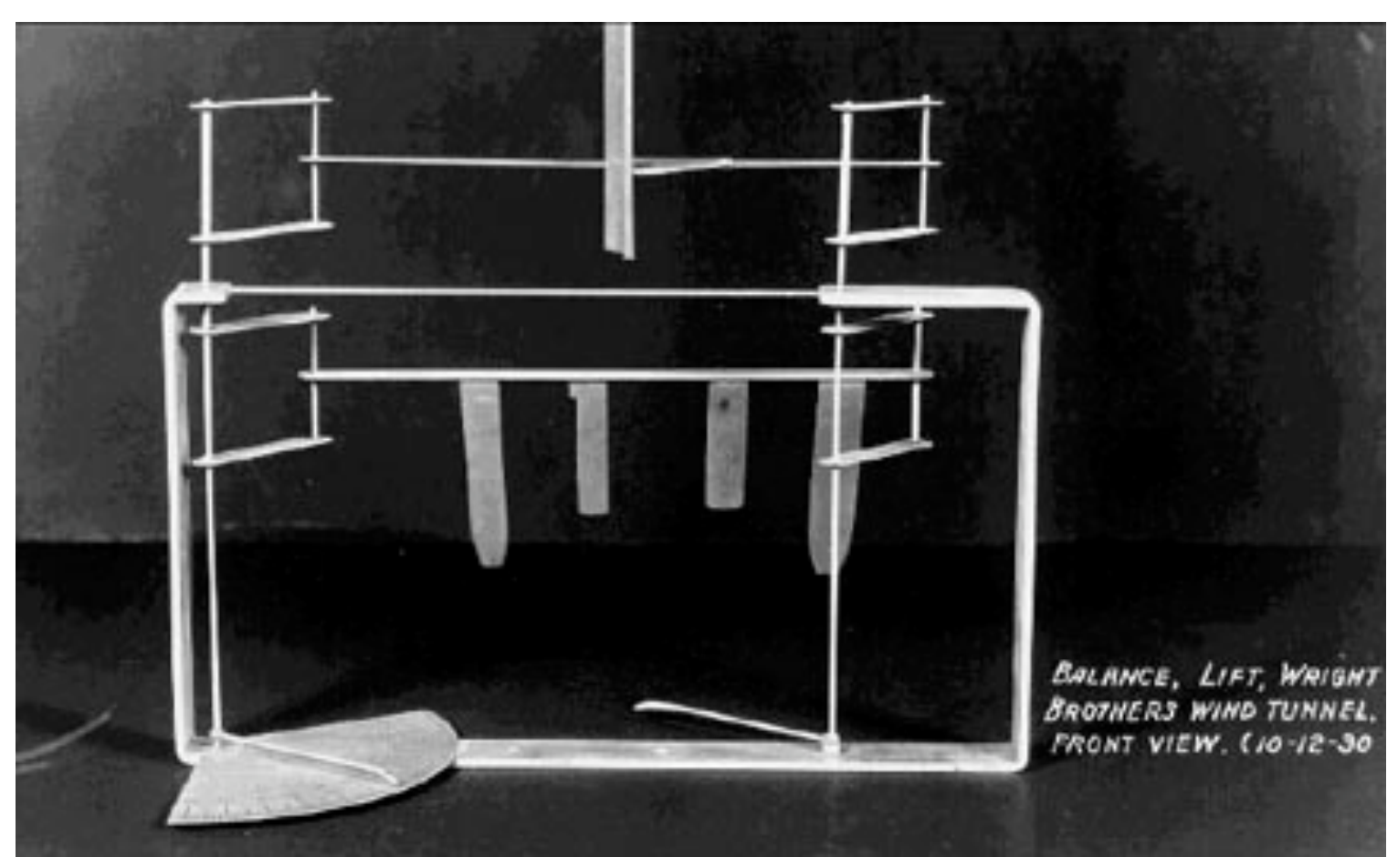

Figure 1: Force balance used in Wright Brothers' wind tunnel.

In the early $20^{\text {th }}$ century in Europe, the main users of wind tunnels were Gustave Eiffel in France and Ludwig Prandtl in Germany. Before beginning wind tunnel testing, Eiffel performed aerodynamic tests by dropping objects off his famous tower. Prandtl built the first closed circuit wind tunnel in 1908.

In the United States, the National Advisory Committee on Aeronautics (NACA) oversaw some of the most important advances in wind tunnels including the NACA Variable Density Tunnel (VDT), which was built at the Langley Laboratory in 1921-1923. This was the first wind tunnel that could operate at pressures higher than atmospheric, which allowed higher Reynolds numbers 
to be achieved at lower velocities. By the 1940's supersonic wind tunnels were in use, even though Chuck Yeager had not yet broken the sound barrier. In 1972 a cryogenic wind tunnel was built at NASA Langley by injecting liquid nitrogen into the wind tunnel to cool the gas. This lowered the viscosity and increased the Reynolds number, and this tunnel had the capability to match Reynolds and Mach numbers simultaneously up to Mach 1.2. Today the largest wind tunnel in the world in the National Full-Scale Aerodynamics Complex at NASA's Ames Research Center, which has a test section of cross section $80 \mathrm{ft}$ by $100 \mathrm{ft}(24 \mathrm{~m} \mathrm{x} 31 \mathrm{~m})$. The types of instruments in common use in wind tunnels include boundary layer rakes, tufts, pitot tubes, pressure sensitive paint, smoke, and static pressure taps.

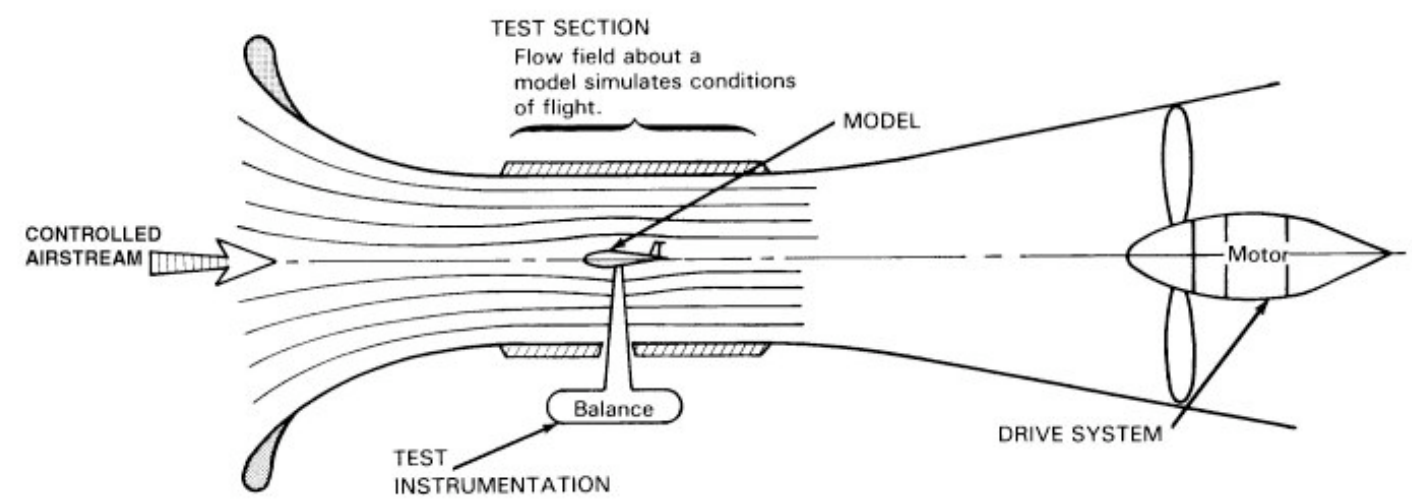

Figure 2: Diagram of typical wind tunnel.

In order for wind tunnel testing with scale models to be applicable to the aerodynamics of the full-scale test object, conditions of dynamic similarity must be met. This typically means that the Reynolds number of the scale model in the test and the actual vehicle in use should match, and if compressibility effects are important, the Mach number should also match. Other issues students should be aware of include the possible aerodynamic interference between support structure and model. One should always measure the drag of the support tare or sting with no model on it first, and then subtract that from the total drag measured with the model in place.

\section{Force Balance Options}

Several different types of force balance are available in general for wind tunnel use:

- Pyramidal balance with full 3 forces and 3 moments

- Sting balance using strain gages

- Direct measurement of lift and drag with load cells

- Simple wire hangar

A full 6-component balance allows for all three forces and all three moments on the model to be measured. Typical costs for commercial force balances are in the thousands of dollars. A twocomponent lift-and-drag balance can be made with two load cells or force transducers. With the addition of a third load cell the pitching moment can also be measured. 


\section{Design Chosen}

Figure 3 shows a picture of the Bradley University Subsonic Wind Tunnel. The test section has a cross sectional area of 11 " by 14 ". The load cells were sized based on the speed and cross section of the Wind Tunnel. Following the rule of thumb that the blockage should be no more than 5\% of the tunnel area ${ }^{1}$, the maximum cross-sectional area of a test model should be 7.7 in $^{2}$ or 0.005 $\mathrm{m}^{2}$. At the maximum speed of $120 \mathrm{mph}(53.6 \mathrm{~m} / \mathrm{s})$, assuming a drag coefficient of 1.0 , this gives a maximum anticipated load of about $2 \mathrm{lbf}(8.6 \mathrm{~N})$. In order to give a factor of safety in case larger objects were used, and also partially to protect from student abuse, a load cell rated for 10 lbf was selected. This was found to also have sufficient resolution for measuring small forces, with a resolution of about $0.01 \mathrm{lbf}$.

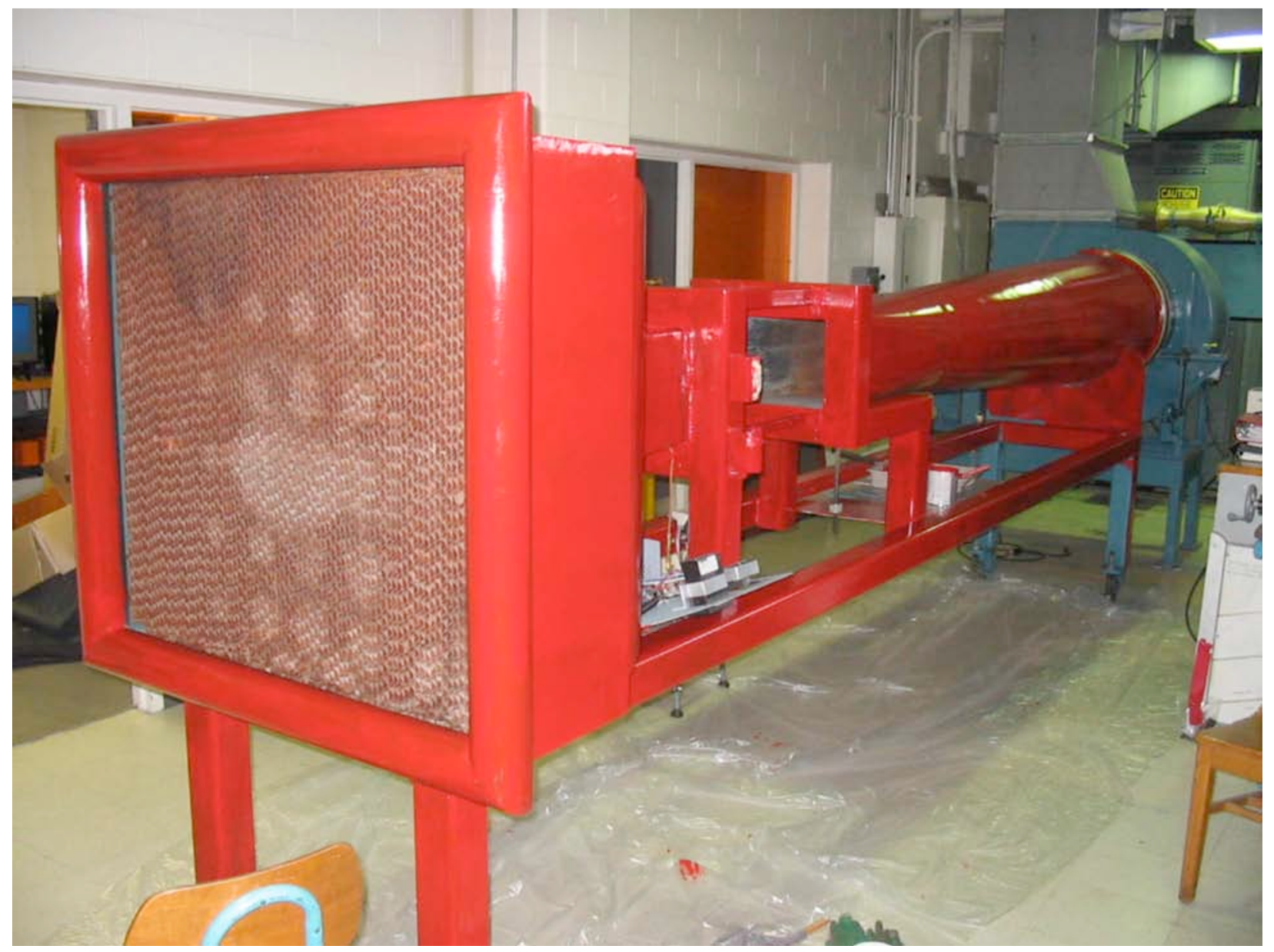

Figure 3: Picture of subsonic wind tunnel upgraded in this work.

While the current design measures only the lift and drag forces, a third load cell could be added relatively easily to enable measurement of the pitching moment as well. Figure 4 shows a CAD drawing of the force balance that was built and added to the wind tunnel shown in Figure 3 . The linear actuator is used to change the angle of attack of airfoil and airplane models. 


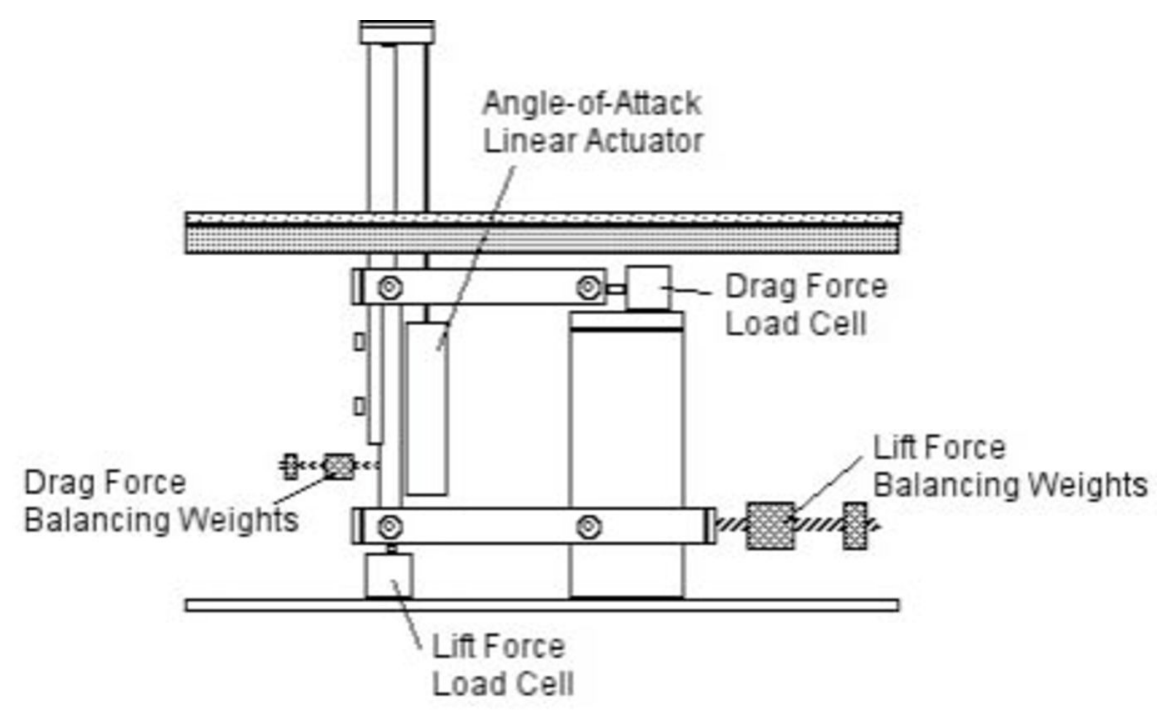

Figure 4: Diagram of Force Balance.

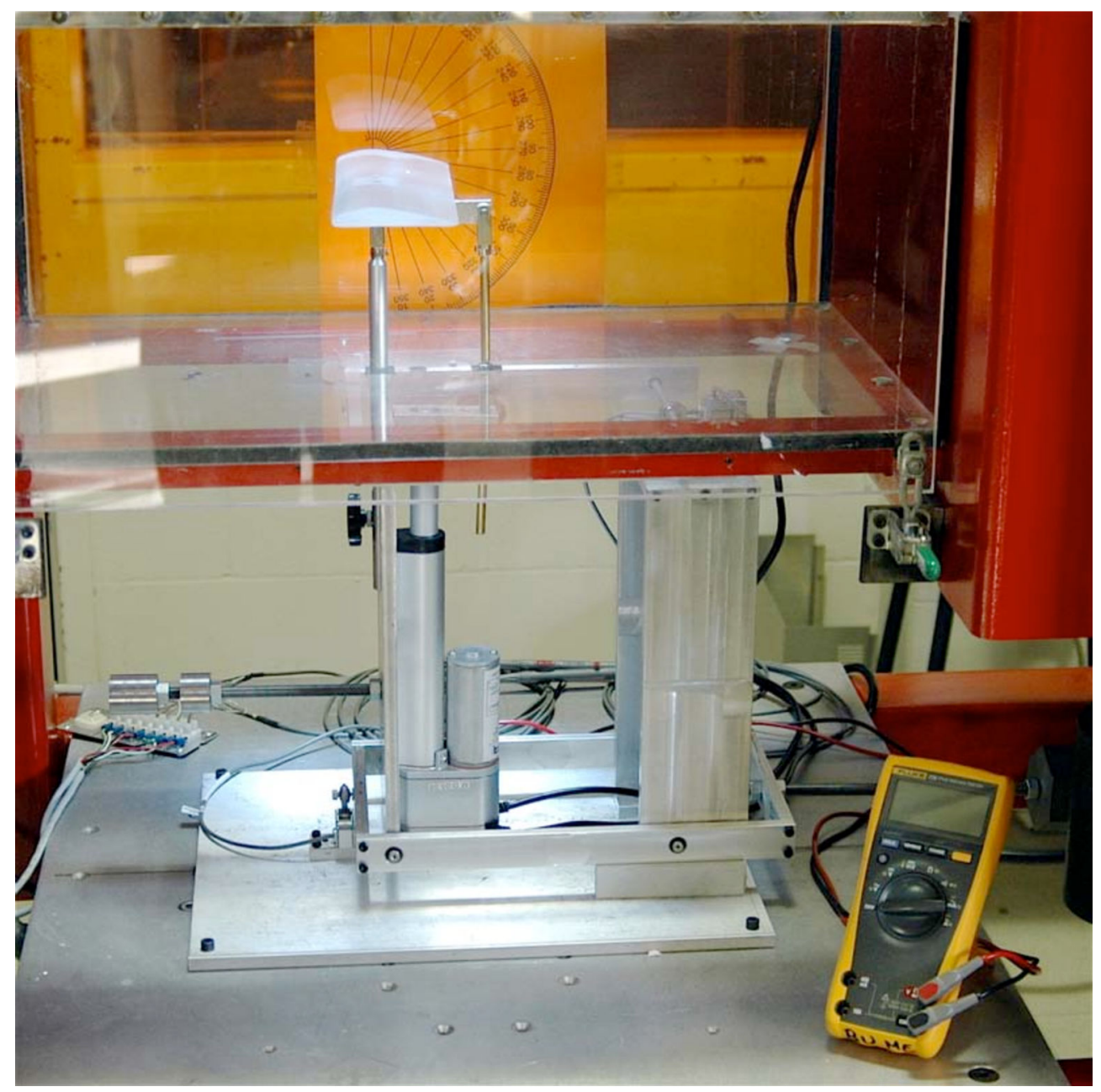

Figure 5: Picture of force balance installed in test section of wind tunnel. 


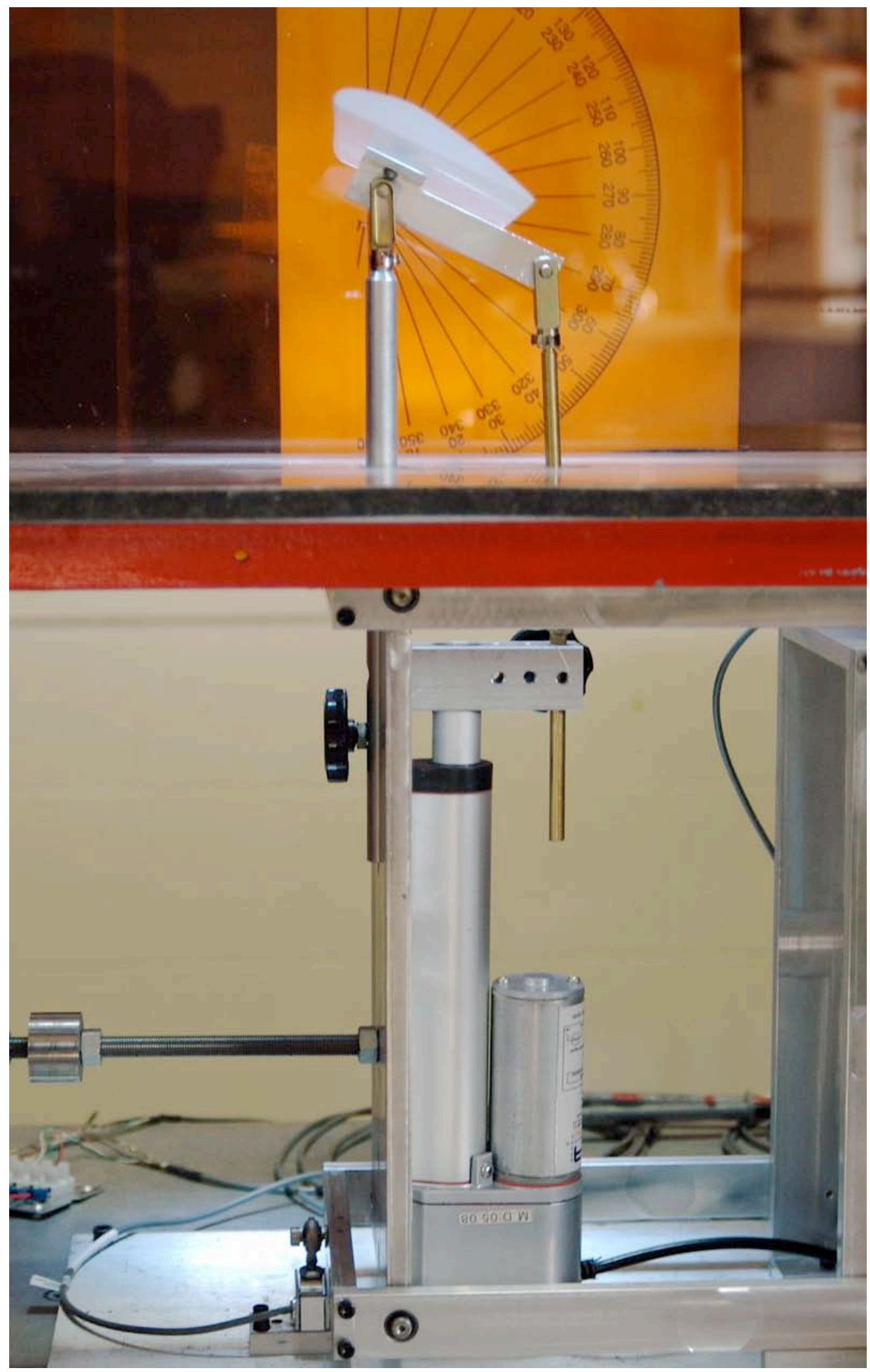

Figure 6: Figure of force balance with linear actuator moved to increase angle of attack.

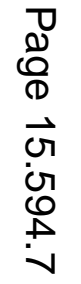




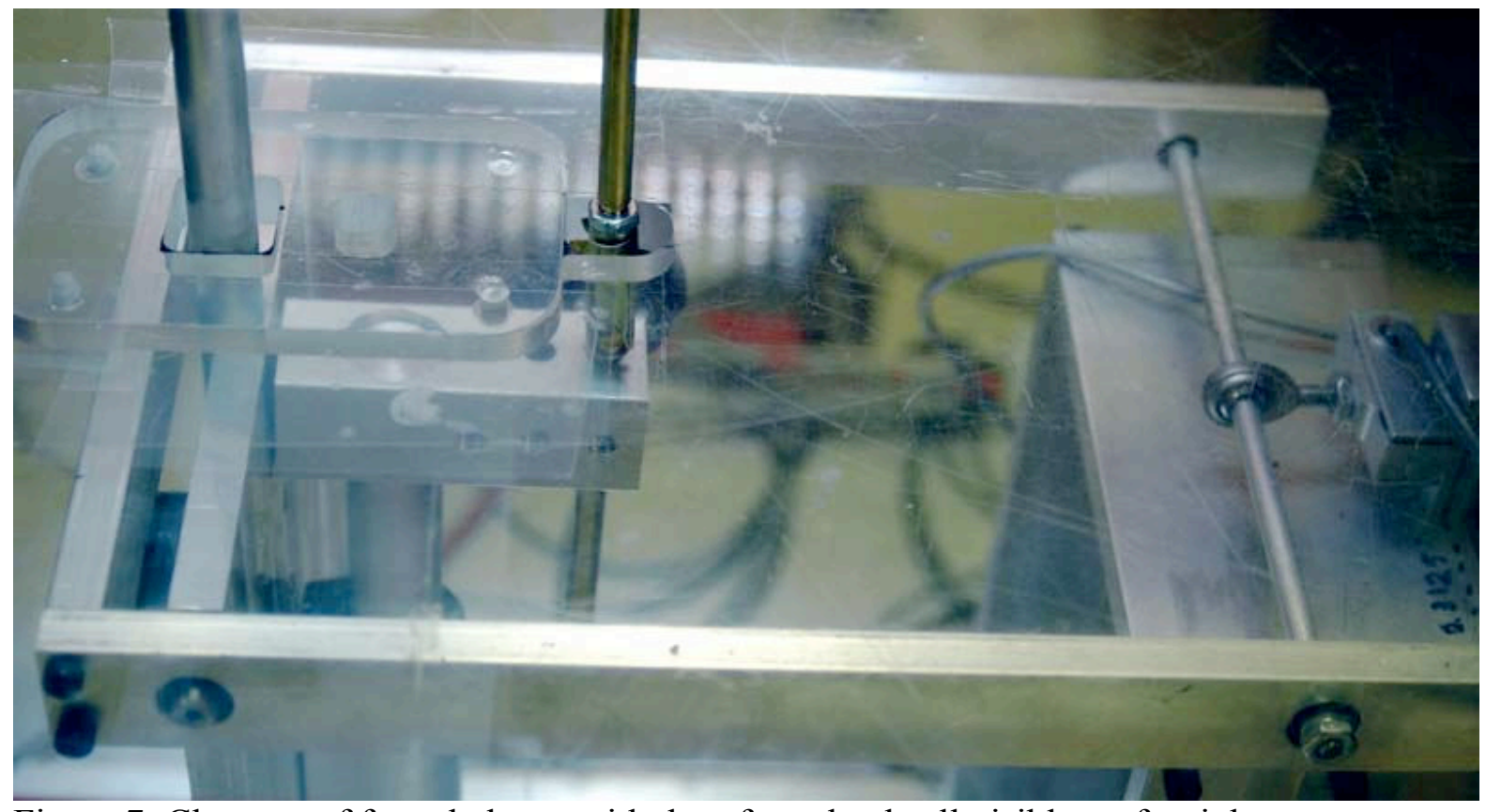

Figure 7: Close-up of force balance with drag force load cell visible on far right.

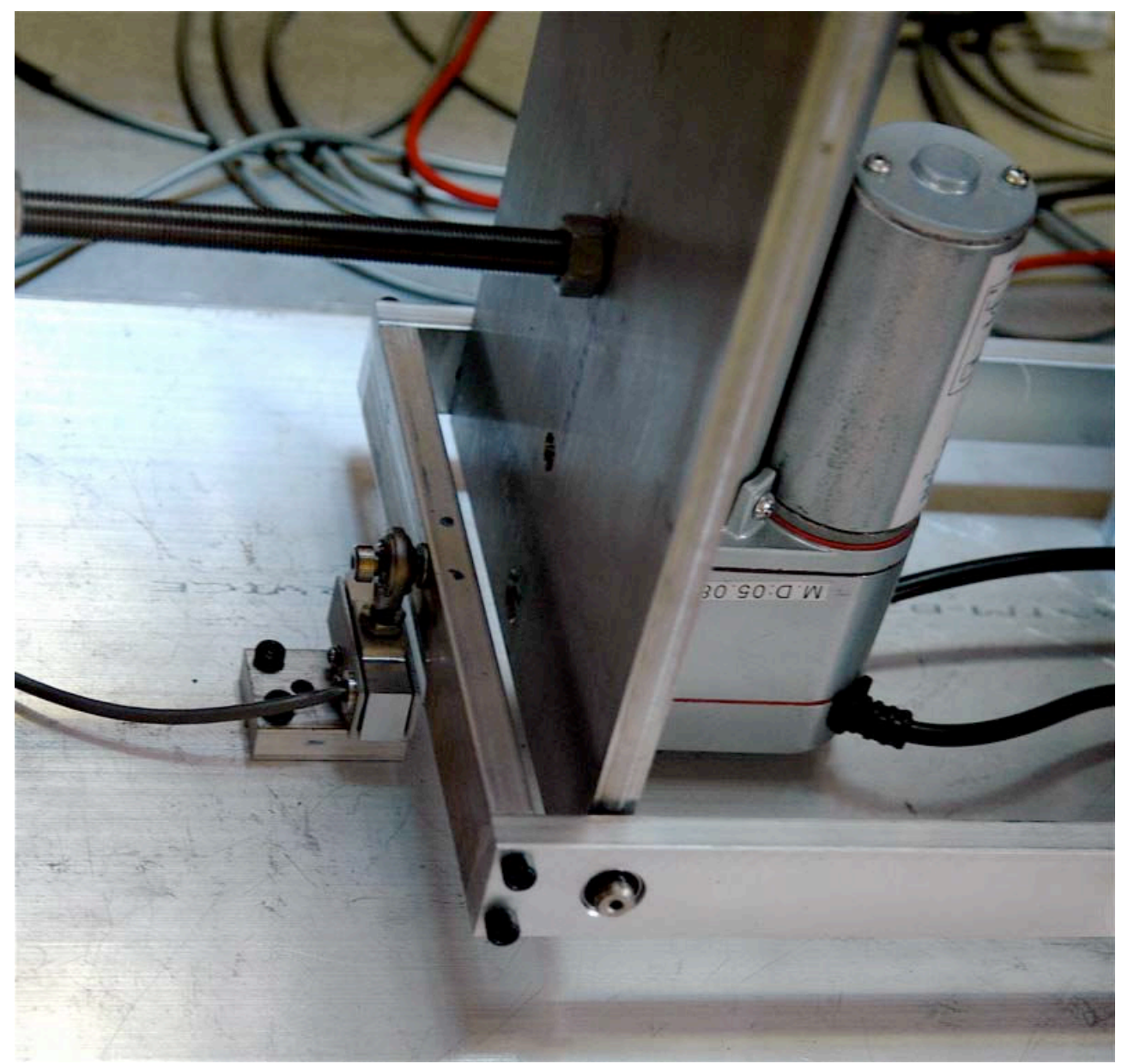

Figure 8: Close-up of force balance with lift force load cell visible on bottom left. 


\section{Costs}

The cost of the components used is given in Table 1. The total cost for the force balance is about $\$ 1000$.

Table 1: Costs of parts to built wind tunnel force balance.

\begin{tabular}{|l|l|l|l|l|}
\hline Item & Vendor & Unit Cost & Number & Total Cost \\
\hline Load Cell & Omega & $\$ 300$ & 2 & $\$ 600$ \\
\hline Aluminum & McMaster-Carr & & & $\$ 300$ \\
\hline Linear Actuator & Firgelli & & 1 & $\$ 175$ \\
\hline Total & & & & $\$ 1075$ \\
\hline
\end{tabular}

The load cells were model LC 703, chosen for the size of the wind tunnel, with a $10 \mathrm{lbf}$ load rating. The linear actuator is model \#FA-PO-150-12-4, with 4 inch stroke and $150 \mathrm{lbf}$ load capacity.

This compares to costs for commercial systems for a two-component balance, comparable to the system described above, with a $10 \mathrm{lbf}$ range, for a total cost of \$9385, including shipping, handling, and a calibration weight set. A price quote was obtained for a 3-component sting balance with a $25 \mathrm{lbf}$ load range and yaw positioning capability for $\$ 14,995$. A full 6-component pyramidal balance with a $50 \mathrm{lbf}$ test range was priced at $\$ 83,400$.

\section{Results}

Testing of airfoils in the wind tunnel with the new force balance show good results, with reasonable and repeatable drag polars obtained. Lift and drag coefficients typically did not change by more than $+/-10 \%$ with varying wind tunnel velocity in the range of Reynolds numbers where the coefficients should be fairly constant.

\section{Conclusions}

The drawings and pictures presented in this paper will allow other engineering educators to copy and build this relatively low-cost design that gives good accuracy and repeatable results for use in student projects. The costs could be further reduced by using cheaper load cells with smaller force ratings.

\section{Bibliography}

1. Barlow, J. B., Rae, Jr., W. H. and Pope, A., Low Speed Wind Tunnel Testing, John Wiley \& Sons, 1999.

2. Anderson, J.D., Introduction to Flight, 4th Ed., McGraw-Hill, 2000

3. Post, S. 2010, Applied and Computational Fluid Dynamics, Jones and Bartlett Publishers.

4. Houghton, E., and Carpenter, P., 2001, Aerodynamics for Engineering Students, Butterworth-Heinemann.

5. Bertin, J., and Cummings, R., 2008, Aerodynamics for Engineers, Prentice-Hall.

6. Hoerner, S., 1965, Fluid Dynamic Drag, self-published.

7. Blevins, R., 2003, Applied Fluid Dynamics Handbook, Krieger. 
8. E. Jacobs, K. Ward, and R. Pinkerton. NACA The Characteristics of 78 Related Airfoil Sections from Tests in the Variable-Density Wind Tunnel. Report 460. 1933.

9. Talay. T., 1975, Introduction to the Aerodynamics of Flight. NASA SP-367. http://history.nasa.gov/SP367/cover367.htm

10. John Rajadas, Bradley Rogers, AC 2007-1191: DESIGN, FABRICATION AND TESTING OF A LOWSPEED WIND TUNNEL LABORATORY

11. D. Baals, and W. Corliss. Wind Tunnels of NASA. NASA SP-440, 1981.

12. Dwayne Day, Centennial of Flight Commission. "The Evolution of the Wind Tunnel." http://www.centennialofflight.gov/

13. Peter L. Jakab. Visions of a Flying Machine - The Wright Brothers and the Process of Invention, Washington and London: Smithsonian Institution, 1990, 